\title{
Heartbeat: early intervention for rheumatic mitral stenosis
}

Rheumatic mitral stenosis (MS) remains the most common type of valvular heart disease worldwide yet there are few studies on optimal timing of intervention in asymptomatic patients. Postulated benefits of intervention before symptom onset include prevention of left atrial dilation, atrial fibrillation (AF) and pulmonary hypertension leading to fewer thromboembolic events, less heart failure, preserved exercise capacity and in improved quality of life. In this issue of Heart, Kang and colleagues ${ }^{1}$ report a randomised clinical trial of in 374 patients with severe MS (valve area $1.0-1.5 \mathrm{~cm}^{2}$ ) comparing early percutaneous mitral commissurotomy (PMC) to conventional care. The primary composite endpoint of PMC-related complications, cardiovascular mortality, cerebral infarction and systemic thromboembolic events occurred in seven patients in the early PMC group $(8.3 \%)$ compared with nine patients in the conventional care group (10.8\%) (HR $0.77 ; 95 \%$ CI 0.29 to $2.07 ; \mathrm{p}=0.61$ ) at a median follow-up of 6 years (figure 1).

Karthikeyan $^{2}$ points out that there is only a sparse evidence base for management of mitral stenosis. Although this study by Kang and colleagues ${ }^{1}$ is commendable, replication in larger studies in countries with endemic rheumatic heart disease is needed. In the meanwhile, 'even minimally symptomatic patients with severe MS often deteriorate, due to AF and fast ventricular rates, triggered by drug noncompliance or inter-current illness. In such situations, patients may not have timely access to acute care (and emergency PMC), which may be life-saving. Therefore, a case can be made for performing early PMC in asymptomatic patients with significant MS ( mitral valve area $\leq 1.5 \mathrm{~cm}^{2}$, or $\leq 1.3 \mathrm{~cm}^{2}$ if body surface area is $<1.5 \mathrm{~m}^{2}$ ), provided the procedure can be performed safely (procedure-related death or mitral regurgitation requiring surgery $<3 \%$ ). Close medical follow-up should be reserved for patients in sinus rhythm, without evidence of left atrial hypertension, or a propensity

Division of Cardiology, University of Washington, Seattle, Washington, USA

Correspondence to Professor Catherine M Otto, Division of Cardiology, University of Washington, Seattle, WA 98195, USA; cmotto@uw.edu

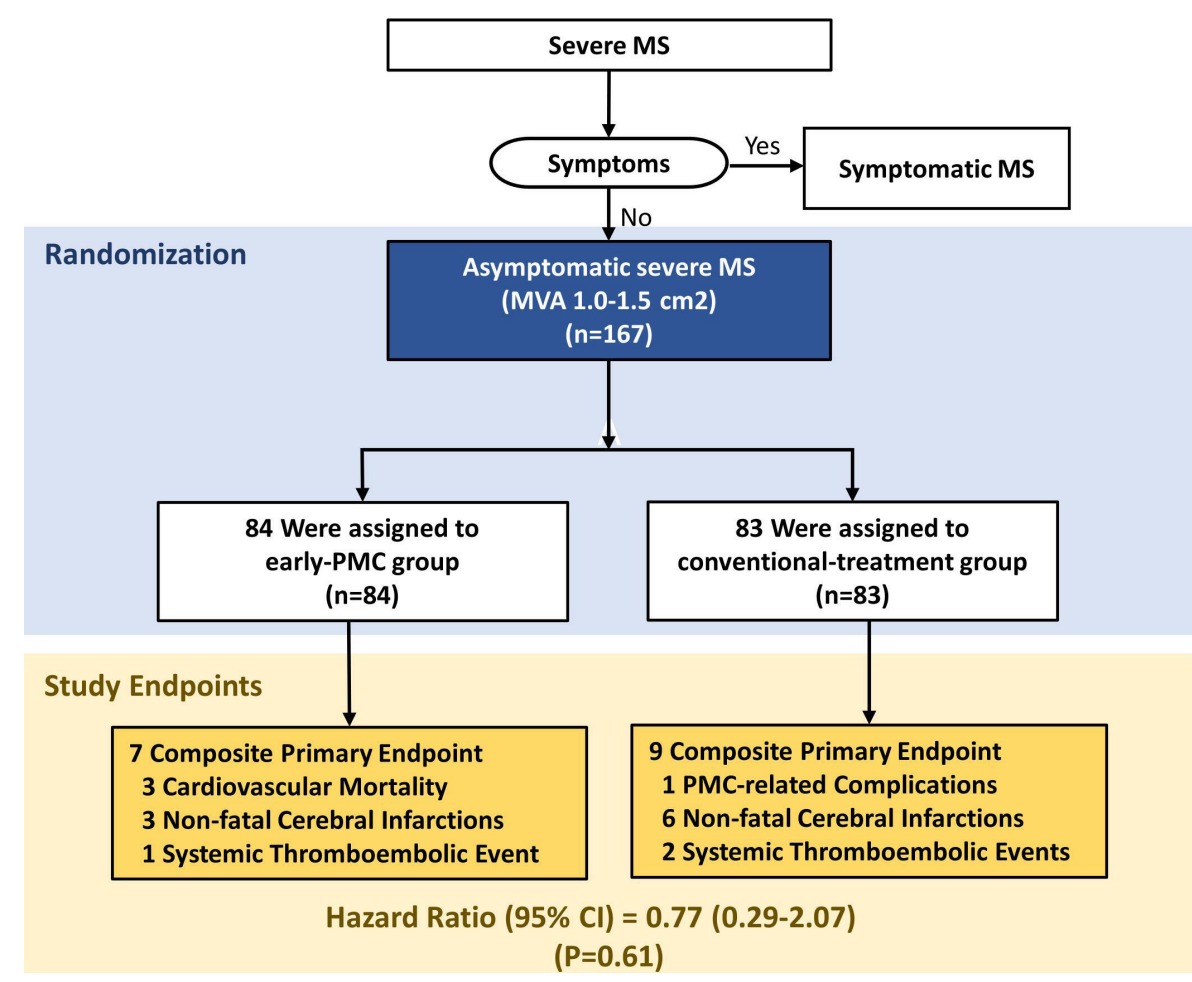

Figure 1 Summary of the MITIGATE (mitral intervention vs conventional management in asymptomatic mitral stenosis) trial. MS, mitral stenosis; PMC, percutaneous mitral commissurotomy.

A GLOBAL COHORT

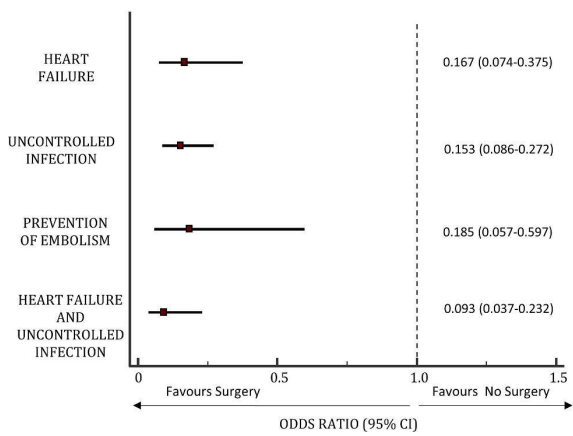

B PROPENSITY SCORE MATCHED COHORT

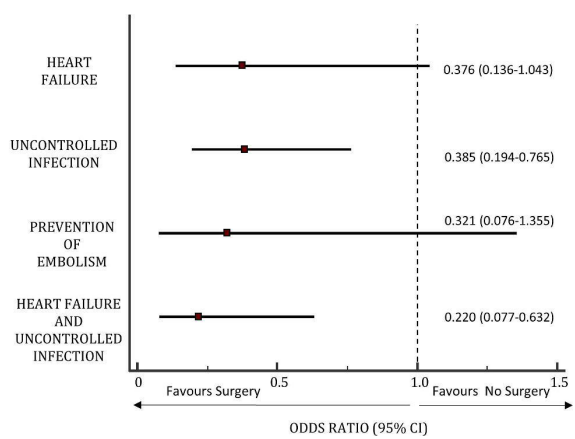

Figure 2 Association between cardiac surgery and in-hospital mortality according to the surgical indication.

for haemodynamic deterioration or systemic embolism.'

Also in this issue of Heart, Garcia Granja and colleagues ${ }^{3}$ present an observational study of 605 patients with left-sided infective endocarditis. The 405 patients who underwent surgery during the active phase of the disease were compared with the 200 who received only medical therapy. On multivariable analysis, early surgery was a independent predictor of survival (OR 0.260 , 95\% CI 0.162 to 0.416 ), particularly in those at highest risk (predicted mortality 80\%-100\%: OR 0.08, 95\% CI 0.021 to 0.299 ) and those with uncontrolled infection (figure 2).

In the accompanying editorial, Donal and colleagues ${ }^{4}$ discuss the limitations of this study and provide the context that in 'the largest retrospective study provided 


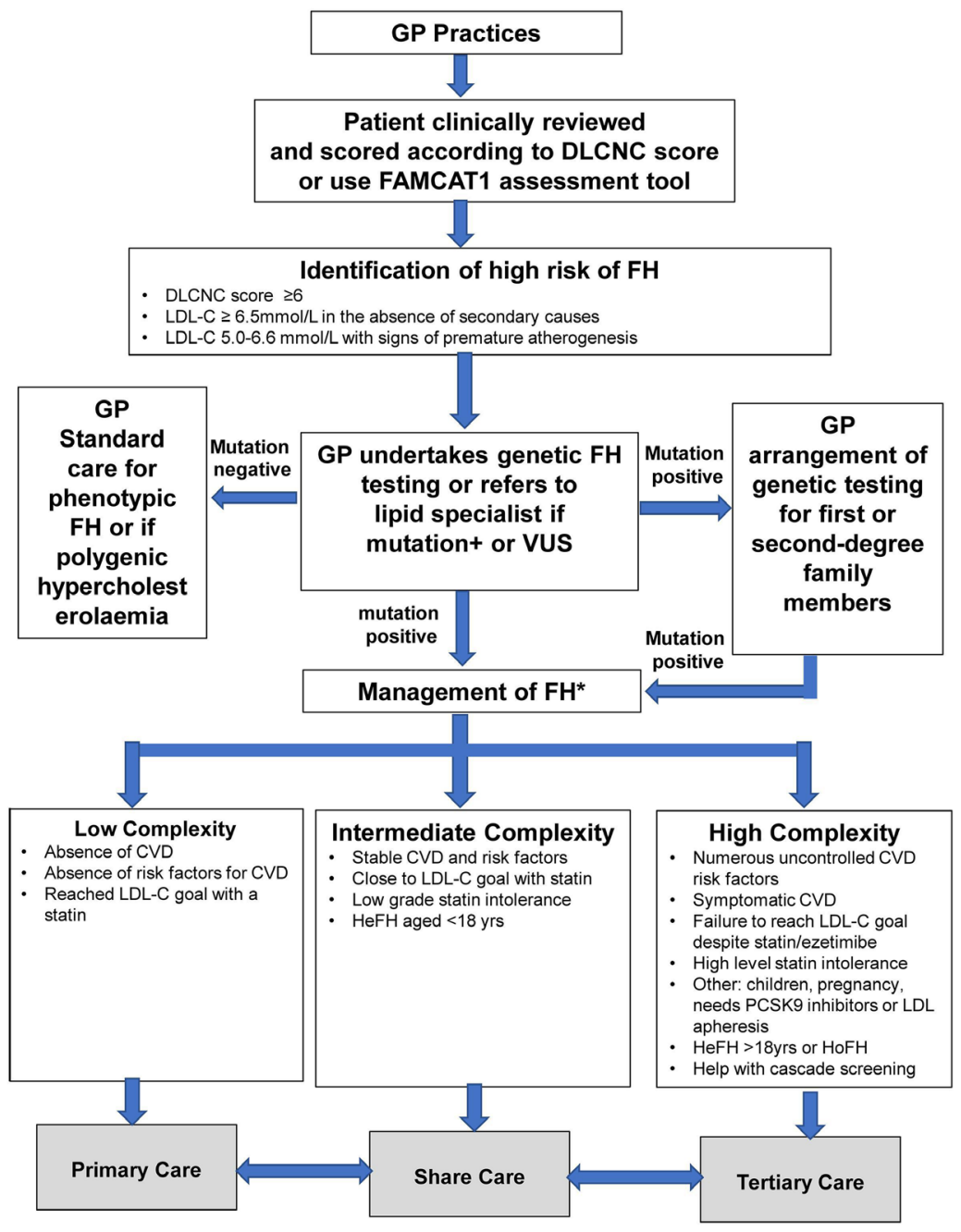

Figure 3 Ascertainment tool. CVD, cardiovascular disease; FH, familial hypercholesterolaemia; $\mathrm{GP}$, general practitioner; $\mathrm{HeFH}$, heterozygous $\mathrm{FH}$; $\mathrm{HoFH}$, homozygous $\mathrm{FH}$; LDL-C, low-density lipoprotein-cholesterol; PCSK9, proprotein convertase subtilisin/kexin type 9; VUS, variant of uncertain significance, * Refer to Sturm et al ${ }^{10}$ and Brett T et al ${ }^{11}$ DLCNC, Dutch Lipid Clinic Network Critieria; FAMCAT1, familial hypercholesterolaemia case ascertainment tool.

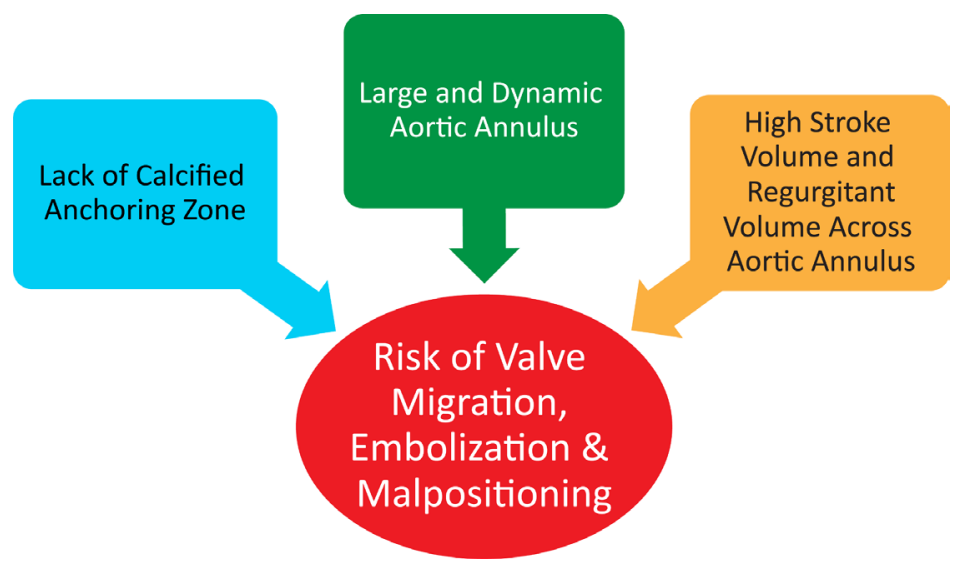

Figure 4 Challenges of performing transcatheter aortic valve implantation in isolated aortic regurgitation. Key anatomic and physiological aspects of isolated aortic regurgitation which contribute to technical challenges during transcatheter aortic valve implantation are shown. by the International Collaboration on Endocarditis consortium: the comparison of early cardiac surgery vs conservative management was neutral." Even so, they conclude that the study by Garcia Granja et $a l^{3}$ brings 'another piece of evidence that left-sided endocarditis is a disease that requires rapid, well-organised and expert teams for an early diagnosis, early decision-making process and very early access to the operating room and to the intensive cares required to save, undoubtedly, lives!'

The optimal approach to detection of familial hypercholesterolaemia (FH) remains controversial. $\mathrm{FH}$, a preventable cause of cardiovascular disease, is present in about $0.4 \%$ of the population suggesting that early detection and treatment would impact public health. Qureshi et $a l^{5}$ applied the FH Case Ascertainment Tool (FAMCAT1) to the electronic medical records of over 82 thousand patients. Of the $4 \%$ identified as having a high risk of $\mathrm{FH}, 283$ patients agreed to genetics testing which found pathogenic variants in 16 and variants of uncertain significance in 10 patients, matching the expected population prevalence of this condition. All these patients were referred for specialist care. An additional 153 patients were found to have polygenic hypercholesterolaemia and were managed by primary care.

In an editorial, Brett and Watts ${ }^{6}$ help make sense of the various proposed approaches for diagnosis of $\mathrm{FH}$, discuss the balance between primary and specialist care, and provide a useful algorithm for clinical practice (figure 3). In order to diagnose and treat all cases of $\mathrm{FH}$, they suggest 'A new approach, possibly involving some form of universal screening in youth combined with reverse cascade testing or even population-based genomic testing, will be needed.'

A provocative Point and Counterpoint set of articles addresses transcatheter aortic valve implantation (TAVI) versus surgical aortic valve replacement (SAVR) in patients with native valvular aortic regurgitation (AR). Kahn and Baron ${ }^{7}$ conclude that "while a dedicated transcatheter device for the treatment of $\mathrm{AR}$ is ideal, there is a clear need now for percutaneous aortic valve treatment in the subset of patients with AR who cannot undergo SAVR. With appropriate patient selection, careful device sizing and optimal intraprocedural imaging and techniques, TAVI using currently available devices off-label has demonstrated reasonable outcomes and offers a viable therapeutic option for this previously untreated patient population.' In contrast, 
Huded et $a l^{8}$ conclude 'TAVI for AR is becoming increasingly feasible with newer generation devices, but outcomes still lag behind the high benchmark established for TAVI in patients with AS. There are no randomised controlled trials and no midterm data to support the routine application of TAVI for isolated AR' (figure 4). Taken together, these two articles provide a thoughtful and comprehensive review of the current literature.

The Education in Heart article in this issue ${ }^{9}$ provides a clear approach to distinguishing ventricular tachycardia from supraventricular tachycardia in patients with a wide complex tachycardia. This article also provides a summary of the numerous proposed algorithms for differentiation of ventricular from supraventricular tachycardia in clinical practice.

Funding The authors have not declared a specific grant for this research from any funding agency in the public, commercial or not-for-profit sectors.

Competing interests None declared.
Patient and public involvement Patients and/or the public were not involved in the design, or conduct, or reporting, or dissemination plans of this research.

Patient consent for publication Not applicable.

Provenance and peer review Commissioned; internally peer reviewed.

(c) Author(s) (or their employer(s)) 2021. No commercial re-use. See rights and permissions. Published by BMJ.

\section{(A) Check for updates}

To cite Otto CM. Heart 2021;107:1925-1927.

Heart 2021;107:1925-1927.

doi:10.1136/heartjnl-2021-320535

\section{ORCID iD}

Catherine M Otto http://orcid.org/0000-0002-05279392

\section{REFERENCES}

1 Kang D-H, Park S-J, Lee S-A, et al. Early percutaneous mitral commissurotomy or conventional management for asymptomatic mitral stenosis: a randomised clinical trial. Heart 2021;107:1980-6.

2 Karthikeyan G. Early intervention for asymptomatic mitral stenosis: a stitch in time? Heart 2021;107:1931-2.
3 Garcia Granja PE, Lopez J, Vilacosta I, et al. Prognostic impact of cardiac surgery in left-sided infective endocarditis according to risk profile. Heart 2021;107:1987-94.

4 Donal E, Flecher E, Tattevin P, et al. Cardiac surgery in any context of left-sided infective endocarditis? Heart 2021;107:1933-4.

5 Qureshi N, Akyea RK, Dutton B, et al. Case-Finding and genetic testing for familial hypercholesterolaemia in primary care. Heart 2021;107:1956-61.

6 Brett T, Watts GF. Familial hypercholesterolaemia: genetic testing in general practice and beyond. Heart 2021;107:1928-30.

7 Khan SA, Baron SJ. Point: patients with native aortic regurgitation can be treated with transcatheter aortic valve implantation. Heart 2021;107:1938-41.

8 Huded CP, Allen KB, Chhatriwalla AK. Counterpoint: challenges and limitations of transcatheter aortic valve implantation for aortic regurgitation. Heart 2021;107:1942-5.

9 Ding WY, Mahida S. Wide complex tachycardia: differentiating ventricular tachycardia from supraventricular tachycardia. Heart 2021;107:1995-2003.

10 Sturm AC, Knowles JW, Gidding SS, et al. Clinical Genetic Testing for Familial Hypercholesterolemia: JACC Scientific Expert Panel. J Am Coll Cardiol 2018;72:662-80

11 Brett T, Radford J, Heal C, et al. Implications of new clinical practice guidance on familial hypercholesterolaemia for Australian general practitioners. Aust J Gen Pract 2021:50:616-21. 